\title{
ENSINO A DISTÂNCIA NO BRASIL: RAIZES HISTÓRICAS E PERSPECTIVAS CIBERNÉTICAS
}

\author{
Nilo Serpa ${ }^{1,2}$ \\ ${ }^{1}$ Instituto de Ciências Exatas e Tecnologia - Universidade Paulista \\ (UNIP) \\ Brasília - DF - Brasil \\ ${ }^{2}$ INDRA-POLITEC Global IT Services \\ Brasília - DF - Brasil \\ niloserpa@gmail.com, nilo@techsolarium.com
}

\begin{abstract}
Resumo. O presente artigo tem por objetivo discutir os rumos do ensino a distância no Brasil, apresentando uma proposta de inteligência artificial a partir de certo posicionamento neo -crítico quanto a real função dessa modalidade instrucional na sociedade do conhecimento, quanto a suas limitações e quanto aos beneficios que potencializa para o público estudante. Sem deixar de apreciar os aspectos históricos do ensino no país, concentra-se tão-somente naqueles que são pertinentes ao contexto da abordagem, dando ênfase na evolução da tecnologia da informação $e$ em seus reflexos sobre a cultura brasileira. Mais do que um estudo descritivo, apresenta as bases sintáticas de uma meta-linguagem para formalização da estrutura funcional do professor cibernético - aquele que simula o comportamento dinâmico do professor humano —, além de fornecer algumas notas autobiográficas intelectuais nas áreas educacional, tecnológica $e$ científica.
\end{abstract}

Palavras-chave: cibernética; inteligência artificial; educação; sociedade do conhecimento; motivação; tecnologia

\section{DISTANCE LEARNING IN BRASIL: HISTORICAL ROOTS AND CYBERNETICAL PERSPECTIVES}

\begin{abstract}
The present article aims to discuss the direction of distance learning in Brazil, presenting a proposal of artificial intelligence based on a neo-critical position about the real function of this instructional method in the knowledge society, as their limitations and benefits for the student public. Without fail to appreciate the historical aspects of education in the country, it focuses only those relevant to the context of the approach, emphasizing the evolution of information technology and its impact on Brazilian culture. More than a descriptive study, it also presents the basis of a meta-language to formalizing the functional structure of the cyber teacher - one that simulates the dynamic behavior of the human teacher -, and provide some author's intellectual biographical notes on education, technology and science.
\end{abstract}

Keywords: cybernetics; artificial intelligence; education; knowledge society; motivation; technology 


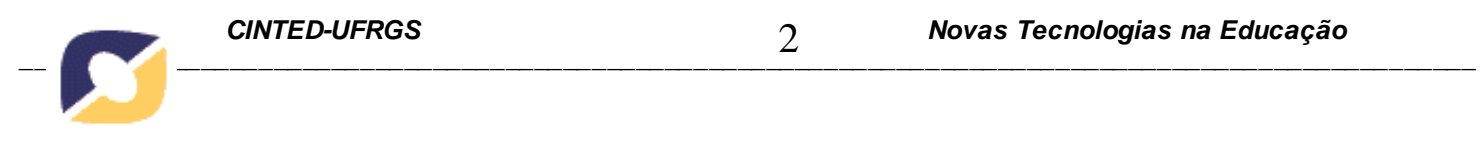

\section{INTRODUÇÃO}

An expert is a man who has made all the mistakes, which can be made, in a very narrow field.

\section{Niels Bohr}

O Brasil vive hoje um dilema na educação. Para chegar à verdadeira potência que almeja ser, mais igualitária, inclusiva e independente, tanto do ponto de vista científico quanto do tecnológico, precisa passar por ampla revisão de processos educacionais em todos os níveis. Para isso, terá que investir grandes somas ao longo de uma transformação que certamente levará décadas. Ao mesmo tempo, como não pode se dar o luxo dessa espera prolongada, o Estado brasileiro lança mão de medidas paliativas imediatistas que agravam suas deficiências, pondo a nu, diante da opinião pública internacional, a fragilidade de seus alicerces sociais. Em pleno século XXI, resiste ainda o bastião da ignorância útil e da deseducação oportuna, ambas alimentadas pelo pensamento amoral, ou pior, imoral, de homens que desprezam valores éticos e que paradoxalmente são postos a ocupar cargos públicos pelos votos de um povo dormente. Inglória tem sido a luta contra a apologia da mediocridade, essa que nos leva a eleger figuras pateticamente cômicas, caricaturas grotescas e mal-ajambradas do sutil e raro artista do riso, colocadas em posições que jamais ocupariam numa sociedade competente, jactando-se de suas falsas proezas no palco da miséria humana que lhes serviu de meio de vida. A televisão, outrora aliada indispensável para a realização de telecursos e entretenimentos diversos para todas as idades em horários adequados, hoje transformada em inimigo íntimo, traduz por sorrisos enlatados e encomendados a peso de ouro o mau gosto quase pornográfico de uma programação apresentada por indivíduos para os quais o menor esforço de raciocínio seria letal. Triste democracia que não se soube alcançar; nunca "liberdade" foi uma palavra tão vazia de sentido. Mesmo a música, arte transcendental de natureza inefável, parece agora nunca ter servido à educação; a Capital Federal, por exemplo, é surda para ela. O que resta por toda parte é o barulho das abomináveis duplas pseudo-sertanejas com seus grasnos semitonados e todo o seu ódio pela cultura popular e pela harmonia. Tediosas e vulgares linhas melódicas se repetem ininterruptamente, sonorizando mensagens vácuas, sem poesia, dando lições de ignorância musical, léxica e estética, sem dúvida proveniente de níveis de percepção cultural abaixo da crítica. Como se pior não fosse possível, me vejo aterrado com o grotesco fim de tão suprema arte nos ruídos e vociferos dos funks. Sou obrigado a concordar com Pierre Lévy, quando ele diz que,

"Quando escutamos os japoneses tocando Beethoven, ou os chineses cantando Verdi, não devemos pensar que eles foram seduzidos pela música 'ocidental'. Essa música não é 'ocidental', é universal, e isso porque ela pode tocar o coração de todos". (Lévy, 2001).

É a capacidade de sentir o coração tocado pela música que se perdeu com a ausência da educação. Sem essa capacidade, o espírito se torna presa fácil da frivolidade, do mau-gosto, do bizarro. Como diria o grande Villa-Lobos, se por aqui estivesse: "a humanidade precisa voltar a escutar o seu coração!”. 
Frivolidades dominantes e mau-gosto generalizado são subprodutos de um processo irrefletido de contaminação contra-cultural iniciado nos anos 60 e fundado no repúdio irracional a qualquer coisa originada no pensamento lógico. Mario Bunge (1980) ressaltou uma espécie de "rebelião contra a razão", dizendo ele que "esta se propagou entre a juventude norte-americana e, em parte também, a européia, como parte do movimento contestatório gerado pela intervenção dos Estados Unidos no Vietnam. A desconfiança e mesmo o ódio pela ciência, e a concomitante popularidade da pseudociência e do ocultismo, não têm paralelo na história cultural moderna do ocidente. [...] Esta reação anticientífica se propagou pela Europa e está virando moda no Terceiro Mundo". Ficam assim claras as principais causas do abandono da leitura de boa qualidade e do desaparecimento das motivações acionadas pela razão e pelo bom-senso.

Sempre trago para debate o problema da educação, o que leva o leitor a esperar que eu empregue a expressão educação a distância, e não ensino a distância. Contudo, ainda prefiro a segunda opção. Ensino é algo mais abrangente, e, cautelosamente, menos ambicioso nesse momento. Entendo educação como um processo laboral de agregação organizada, continuada e gradativa de conceitos e valores culturais, mediada por um canal responsável, no intuito de construir e aprimorar o cidadão para que tenha uma vida saudável e produtiva nos planos individual e social. Por enquanto, não creio que tenhamos isso a distância. Os recursos de comunicação de massa se prestam hoje mais à "deseducação a distância". Ainda resta muito a fazer para vivenciarmos de fato educação a distância. De certo que, diante do panorama nada animador que descrevi brevemente, o ensino a distância $(\mathrm{EaD})$ poderá ser importante instrumento telemático de oposição à apatia educacional na qual mergulhou a sociedade brasileira, desde que utilizado com sabedoria, não como solução de todos os males. Tenho discutido reiteradas vezes o fato de que certas aplicações de $\mathrm{EaD}$ necessitam evoluir bastante no sentido da introdução de fortes componentes de inteligência artificial para que, enfim, possam servir à educação stricto sensu. Deixar claro este discurso em meio a uma explanação concisa de idéias originais é também missão que abraço ao longo do presente tratado.

Quero encerrar a introdução ressaltando que considero este artigo uma peça humanística, onde ciência, história e filosofia se combinam para amalgamarem a contribuição original do autor, resultante de anos de dedicação ao assunto e, sobretudo, à educação de maneira geral. Ao longo desta jornada, como físico teórico e consultor na área de tecnologia da informação, sempre busquei motivar meus alunos para o trabalho criativo, mostrando a importância da autenticidade, da honestidade, da franqueza e da conservação do espírito lúdico da infância como forma de nos atirarmos de peito aberto às questões que este conturbado mundo em que vivemos nos apresenta, tornando-os conscientes de que não há teorias isentas de subjetividade, e que esta deve ser tão somente um instrumento íntimo de escolha pessoal do ferramental a ser utilizado para uma descrição objetiva da realidade. Afinal, o que nos distingue como indivíduos são nossas preferências e pendores, responsáveis pelos incontáveis matizes com os quais pintamos as coisas exteriores; sem opiniões pessoais bem elaboradas que nos conduzissem a formular hipóteses e teorias, provavelmente ainda estaríamos pensando em éter e miasmas. Aliás, diga-se de passagem, deveríamos incentivar muitíssimo mais o pensamento criativo; se bem que a criatividade seja reconhecidamente um traço individual mais do que desejável para o exercício das modernas carreiras de gestão, o que de fato se constata é que a cultura contemporânea está 
se tornando um caudal de mesmices impregnado de tecnologia e superficialidade, com ralo teor humanístico. Ao invés de caudatários do comportamento massificado, nossos alunos precisam despertar para a necessidade de inventar e reinventar as formas com as quais interagimos com espírito e matéria. Aos meus leitores e prováveis críticos, deixo a certeza de que jamais abandonarei a responsabilidade de pensar livremente e de expressar minha visão de mundo com a mesma ética profissional que dediquei às gerações de estudantes e aprendizes que pelas minhas classes passaram.

\section{PANORAMA SÓCIO-TECNOLÓGICODO MUNDO OCIDENTAL DO PERÍODO PÓS-GUERRAS}

Traçar um histórico, por resumido que seja, é tarefa difícil. Muitas vezes precisamos contextualizar os fatos não apenas no tempo, mas numa variável psicológica que referencia nossas próprias convicções sobre os aspectos que constituem o pano de fundo do objeto mirado, conquanto se saiba ser impossível abranger tudo em espaço limitado. Só assim conseguimos nos aproximar do entendimento desejado. Esta seção não pretende compendiar o tema, tão somente fornecer um panorama do processo evolutivo da sociedade em seu estágio de informatização, mostrando alguns dos principais pontos de ruptura paradigmática em TI e seus reflexos no chamado "ensino a distância".

As gerações que se engajaram na informática durante os anos 70 e 80 vivenciam hoje o que talvez seja experiência única na história das revoluções da humanidade: a transição entre a sociedade, digamos, clássica, que teve seu auge com o advento da revolução industrial, e a sociedade cibernética, cujo destino se torna cada vez mais impreciso conforme os ditames nem sempre desejáveis da globalização. É evidente que o Brasil não poderia ignorar a necessidade de modernização em larga escala dos seus modelos de informação, tanto por uma questão de adequação ao cenário internacional quanto pela urgência interna em se encontrar caminhos e respostas rápidas para os grandes problemas que se abatem de maneira crônica sobre nossa sociedade.

A evolução social da humanidade se assenta fundamentalmente em uma trilogia de valores da ação humana nos seguintes planos: comunicacional, informacional e gnosiológico. O estudo detalhado dessa evolução fugiria ao âmbito do presente artigo, de maneira que vou me ater ao mundo pós-guerra, enfatizando a dinâmica das relações de trabalho desde os anos 50 até os dias atuais.

A partir da segunda metade do século $\mathrm{XX}$, as transformações sociais tiveram lugar num ritmo jamais registrado. Em uma afirmação quase profética, Peter Drucker (1992) anteviu que em 50 anos, "schools and universities will change more drastically than they have since they assumed their present form 300 years ago when they organized themselves around the printed book". Tão acelerado tem sido o processo de mudança dentro das culturas que se tornou impraticável, senão até destituído de sentido, caracterizar estágios evolutivos nítidos; múltiplas e sucessivas rupturas de paradigmas ocorrem a curtos intervalos, dando-nos a impressão de que não somos capazes de acompanhá-las. Em parte não somos mesmo, o que nos causa uma desconfortável sensação de ansiedade. No entanto, 
em que pese toda a dificuldade de focagem, é possível destacar dominâncias, características gerais que se mostram marcantes e mais ou menos prevalentes sobre as mais diversas atividades humanas ao longo de determinado período.

De acordo com meu modo de ver, nos últimos sessenta anos experimentamos pelo menos três grandes dominâncias em três fases sociais globais, a saber: 1)- hermetismo (sociedade da comunicação), 2)- especialismo (sociedade da informação) e 3)- ecletismo ou holismo (sociedade do conhecimento).

A sociedade da comunicação (dominância do plano comunicacional), predominante nas décadas de 50 e 60, chegando a meados dos anos 70, espelhava a ênfase cultural nos meios de comunicação. Em certo sentido foi o auge da era industrial, com importantes aquisições tecnológicas logo postas ao alcance das grandes massas; foi também o tempo de clássicos como "Os meios de Comunicação" de Marshall Mcluhan (1911-1980) e "Lingüística e Comunicação" de Roman Jakobson (1896-1982). Considera-se que o início efetivo do EaD no Brasil ocorreu nessa fase, em 1969, com a inauguração da TV Cultura e da Rádio Cultura, ambas pertencentes à Fundação Padre Anchieta.

Embora estivesse a humanidade prestes a experimentar uma revolução cultural capaz de modificar radicalmente as crenças do homem até então, no campo da educação a formação superior seguia no mundo ocidental sob influência do antigo modelo tradicionalista dos filhos que seguem as carreiras de seus pais. Tão simples assim, estudo e profissão guardavam uma relação de univocidade; obtinha-se o grau para seguir a carreira correspondente. Era praticamente inconcebível que alguém deixasse de exercer a função para a qual havia se preparado em favor de outra atividade, salvo por motivos extraordinários. Qualquer especialização, quando desejada, não era mais do que um mergulho do indivíduo dentro da própria clausura intelectual: engenheiro civil especialista em cálculo estrutural, arquiteto especialista em tesouras de telhados e assim por diante, sem janelas para a interdisciplinaridade e com pouca amplitude humanística. É claro que no pensamento científico havia mais abertura. Já a linguística, tal como a concebia Edward Sapir (1884-1939), exibia nexos com outras disciplinas científicas, e, segundo ele mesmo dizia do lingüista da época, "a menos que the falte certa dose de imaginação, não pode deixar de participar de alguns ou de todos os interesses interdisciplinares que ligam a linguiística à antropologia e à história cultural, à sociologia, à psicologia, à filosofia, e, mais remotamente, à fisiologia e à física". A prática científica, pela sua própria natureza, exige essa abertura, mas, no contexto geral do processo civilizatório, representa uma parcela de atividade muito pequena na sociedade. Analogamente, no mundo das artes seletos olhares vêem muito além da realidade mais imediata e transcendem o pensamento linear. Enfim, na sociedade da comunicação o mercado de trabalho ainda absorvia relativamente bem a oferta universitária.

Na sociedade da informação (dominância do plano informacional), a partir de 1975-76 até início da década de noventa, o perfil predominante foi o do especialista por excelência. Não bastava uma determinada formação. Se exigia uma perícia (expertise), uma total concentração no foco escolhido, deixando assim ainda menos espaço intelectual para a interdisciplinaridade. $\mathrm{O}$ mercado de trabalho valorizava o investimento pessoal em deter certo conhecimento específico, mas o modelo acabou deteriorado pela fragmentação 
exagerada das áreas de especialização ao ponto de deixar um rastro de estereótipos profissionais que ainda hoje deformam e prejudicam o andamento das atividades corporativas governamentais. $\mathrm{O}$ resultado de tamanha compartimentação foi desastroso para quem precisou se adequar a um mercado muito mais volátil, saturado e infestado de modismos metodológicos. Os problemas a serem atacados haviam se tornado muito mais complexos no ocaso do século passado e já não se podia mais esperar por soluções unilaterais. Criatividade e adaptabilidade tornavam-se cada vez mais qualidades imprescindíveis ao profissional, anunciando uma rápida e arrebatadora mudança de paradigma.

$\mathrm{Na}$ sociedade do conhecimento (dominância do plano gnosiológico), que pouco a pouco se afirma desde meados dos anos 90, a atitude preponderante é generalista e construtivista, dando ênfase a uma visão panóptica capaz de perceber a trama de interações que envolve o mundo informatizado e globalizado. Já não há a obsessão pela especialização típica da década de oitenta. A compreensão de que nenhum conhecimento verdadeiro é isolado e de que existem inúmeras reedições puramente mercadológicas de conceitos que já eram dominados nos anos setenta levam a uma busca frenética pelo novo, por novas incursões em áreas variadas como biologia, computação quântica, ecologia humana, bioética, e outras tantas, ultrapassando em muito os limites tecnológicos da informática cotidiana. A imensa variedade de ações humanas e de estímulos do mundo contemporâneo suscita muito mais um perfil profissional de gestor multifacetado, capaz de realizar antes pela visão universalista que detém do que por um único conhecimento especializado. Os sistemas de informação evoluem no sentido de aguçarem, por assim dizer, a inteligência do tomador de decisão. Foi nessa era do conhecimento suplantando a simples informação que floresceram os principais centros de informática do país, e, por conseguinte, as primeiras experiências com ensino a distância mediado por aplicações de software numa escala significativa.

\section{O ENSINO A DISTÂNCIA A PARTIR DOS ANOS 60}

Em plena sociedade da comunicação, Theodor Nelson lança, no ano de 1965, o seu Projeto Xanadu, atribuindo o nome hipertexto à antiga idéia de criar "textos de textos" como forma de vencer a dificuldade em lidar com muitas informações. Nelson imaginara o hipertexto como uma espécie de ambiente cibernético literário no qual, a partir de textos embebidos em textos, seria possível estabelecer uma ramificação de janelas para informações textuais, sonoras e visuais. O Projeto Xanadu trazia o ideal da criação de uma biblioteca planetária reunindo toda a literatura mundial. A introdução do conceito de hipertexto em experiências educacionais representaria um marco telemático sem precedentes para a evolução do ensino a distância.

O avanço caracterizado pela introdução do conceito de hipertexto foi o principal motor da primeira geração computacional microinformática de ensino a distância em meados da década de 80, o então denominado TBC (Treinamento Baseado em Computador). A sigla TBC (em inglês, CBT - Computer Based Training) ganhou vários sinônimos: 


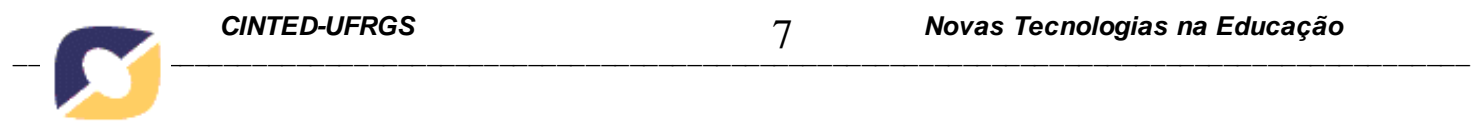

- CSLR (Computer-Suported Learning Resources), aprendizagem com auxilio do computador;

- CAI (Computer-Aided Instruction), instrução assistida por computador;

- CMI (Computer-Managed Instruction), instrução administrada por computador.

O objetivo é o mesmo, qual seja o emprego da tecnologia da informação como suporte ao processo de ensino/aprendizagem. Uma vez que a Internet ainda não havia chegado ao público, a tecnologia de TBC era preferencialmente aplicada de forma adjunta, isto é, complementando atividades presenciais. Nesse momento, já se via a cultura humana em nova transformação, uma vez que, como McLuhan havia observado, a evolução midiática é um elemento fundamental para a própria evolução cultural da humanidade. Precisamente na educação, ela se constitui em fator determinante na expansão da chamada cultura eletrônica; pois, são as formas de pensar o mundo que se modificam pela tecnologia, tornando-se, ao mesmo tempo, agentes de modificação da segunda.

De acordo com Romiszowski (1994), a estrutura do TBC seria classificada conforme três tipos de ambiente: prescritivo, democrático e cibernético. No ambiente prescritivo, os programas não são flexíveis; são em geral desenvolvidos no formato tutorial, com exemplos, exercícios e jogos, sendo a aplicação insensível ao nível de conhecimento do usuário e incapaz de ajustar-se de acordo com a apresentação. $\mathrm{O}$ aluno pode acessar diferentes áreas do aplicativo baseado em seu progresso e em suas habilidades, mas deve proceder por intermédio de um módulo específico antes de dar o passo seguinte. No ambiente democrático, o programa permite ao aluno perceber se está aprendendo e como está aprendendo, ou sobre que assunto está aprendendo; o aprendiz pode optar livremente pela área de sua preferência, movimentando-se por diferentes caminhos até um mesmo final. No ambiente cibernético existe um motor de inteligência artificial gerenciando toda a aprendizagem.

É um erro muito comum ignorar essa fase, passando diretamente do ensino por correspondência e pela televisão para o ensino através da Internet. Os princípios hoje utilizáveis em $\mathrm{EaD}$, tais como os de respostas com feedback, sugestão de rotas de aprendizagem de acordo com o desempenho do aluno, inteligência do sistema para aprender pelas escolhas desse aluno, e outros, foram aplicados e desenvolvidos em TBC. Durante este fértil período, porém, o ensino a distância se limitava às ações de capacitação empresarial stand alone ou em rede local, e ao treinamento específico para o uso de ferramentas de software, ou para aprendizagem básica nas áreas de ciências exatas. Portanto, restringir a história do $\mathrm{EaD}$ ao longo dos anos 80 à oferta de cursos supletivos, no formato de tele-educação, com aulas via satélite complementadas por pacotes de materiais impressos, seria ignorar a vertente cibernética que culminou nas modernas soluções aplicáveis em universidades virtuais.

Não obstante todo o avanço promovido em TBC entre 1984 e 1990, não se verificam nas atuais aplicações de $\mathrm{EaD}$ os principais ganhos tecnológicos em simulações instrucionais obtidos naquela época. Ora, se observarmos atentamente as diferenças técnicas ao longo do 
tempo entre os diferentes produtos desenvolvidos, é razoável admitir que na genealogia clássica do $\mathrm{TBC}$ o moderno $\mathrm{EaD}$ se encontra categorizado como uma especialização ou desmembramento do CSLR. No entanto, pouco se tem visto no Brasil que incorpore inteligência no sentido de estabelecer "redes de sinapses" (falarei delas mais adiante), amarrando o andamento completo do estudo de cada aluno, sugerindo caminhos em função do aproveitamento individual e provendo feedbacks diferenciados para distintas trajetórias de aprendizagem ("dicas" que estimulem a revisão e o acerto, mensagens sugerindo leituras complementares dependendo da rota do aprendiz, etc.). A maior parte dos sistemas de $\mathrm{EaD}$ ainda permanece atrelada a aplicações hibridas de CAI e CMI.

O fator inteligência não é apenas uma sofisticação, mas um determinante do próprio crédito que se atribuirá ao curso, além de suprir a falta do professor humano, não porque se queira, mas porque não há um professor humano disponível para uma teleaula. Afinal, a ausência do mentor senciente onground, capaz de dialogar e prestar esclarecimentos, representa uma severa lacuna que só poderá ser minimizada pela simulação de uma inteligência pedagógica presente. A inteligência simulada atrai o aluno na medida em que este se sente acompanhado, às vezes mesmo com a impressão de estar sendo vigiado. Precisamos lembrar que a abordagem instrucional auto-didática não é adequada para a grande maioria dos estudantes, os quais necessitam de quem os conduza de maneira mais próxima e convincente. Tutor e professor distanciados no espaço e no tempo pode ser uma solução quando se trata de superar barreiras geográficas e dificuldades financeiras, mas não supre o apelo natural ao contato diligente e didático do mestre. Eis que, segundo minha maneira de ver, se justifica considerável parcela de evasão dos cursos a distância nos níveis de graduação e pós-graduação lato senso; sem elementos típicos de inteligência artificial, muitos acabam por perder o interesse. Foi por essa razão que em 1986 desenvolvi a idéia das redes de sinapses.

\subsection{INTELIGÊNCIA ARTIFICIAL EM EaD: O MESTRE CIBERNÉTICO}

É verdade que imitar a inteligência humana é uma ação que pertence antes ao mundo da ficção do que ao mundo real. $\mathrm{O}$ instrutor replicante precisaria imitar a capacidade humana de repetir com paciência, várias vezes se necessário, o mesmo conteúdo sob formas de apresentação distintas. A complexidade do cérebro está acima das possibilidades práticas de simulação, e isso não depende do nível tecnológico, mas sim de restringências impostas pela natureza. Como diria o grande Fred Hoyle (1986), por mais que a ciência e a tecnologia avancem não se poderá fazer com uma pedra muito mais do que se fazia no tempo dos egípcios; as coisas são o que são, se esgotam em si mesmas sem que possamos superar suas restrições naturais intrínsecas. Contudo, como bem observou o prêmio Nobel Herbert Simon, muito da originalidade e variabilidade do comportamento das criaturas vivas se deve à riqueza de seu ambiente e não à complexidade de seus próprios programas internos (Simon, 1965). Partindo desta colocação, torna-se mais objetiva a busca por um simulacro do professor, ainda que extremamente simplificado, porém, concebido no sentido 


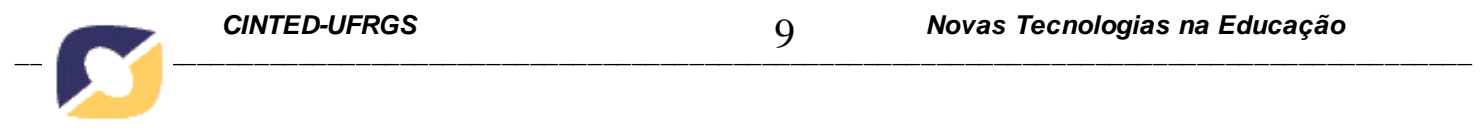

de "captar" a variabilidade do ambiente de ensino/aprendizagem, adaptando-se às mudanças e atuando com certo grau de autonomia.

De acordo com Piaget (1982), inteligência é a capacidade de adaptação do organismo a uma situação nova. Portanto, um sistema instrucional flexível e autônomo, que pode se adaptar às mudanças do aluno e do seu nível de conhecimento, é um sistema inteligente. É assim que, dentro do contexto de orientação a agentes, chega com força o conceito de Agente Inteligente (AI), um pequeno programa que sozinho não conta com muitos recursos, mas que, quando em interação, realiza serviços complexos e eficientes de inteligência artificial (IA). Um sistema computacional baseado em AI é, portanto, constituído por efeituadores que solucionam problemas; são capazes de ações flexíveis, autônomas e socialmente organizadas. Em $\mathrm{EaD}$, o $\mathrm{AI}$ interage com o ambiente do aluno, toma decisões quanto à liberação de materiais instrucionais, envia relatórios analíticos para os supervisores e aprende a partir das decisões do aluno e do supervisor, aperfeiçoando gradativamente seus mecanismos decisórios. Trata-se, portanto, de conceber e construir um sistema de aprendizagem a distância, no qual agentes humanos e artificiais colaboram para o cumprimento da meta instrucional. $\mathrm{Na}$ verdade, o agente instrutor simula parcialmente o professor humano de modo a auxiliar sincronamente os alunos em suas jornadas.

Na segunda metade da década de 1980, Gloria Gery discutia, no âmbito de TBC, o ciclo fundamental - estímulo - resposta - análise da resposta - retroalimentação (feedback) - a ser reproduzido em freqüentes repetições de caráter agregador para a construção do conhecimento, uma vez iniciado o processo de ensino-aprendizagem. Nesse contexto, a autora foi proficiente em sua argumentação esclarecedora sobre interatividade:

\begin{abstract}
"In straightforward terms, interactivity is the incorporation of repetitive, frequent, and meaningful iterations of a stimulus-responseanalysis-feedback cycle into material that is presented in a medium that permits it. Essentially, creating an interactive learning experience is the process of structuring and sequencing variations of this cycle into a series that, when experienced by a learner, results in progress toward knowledge or skill acquisition. Typically, the more interactivity the better, particularly when the interactions are systematically chained together by either the learner or the course to move the learner along the knowledge continuum". (Gery, 1987).
\end{abstract}

Evidentemente, o referido ciclo é intrínseco a qualquer desdobramento instrucional, seja formativo, informativo ou destinado à capacitação específica no formato de treinamento. Mas, como assinalado no fragmento, são as variações do ciclo que determinam em grande medida o progresso rumo ao conhecimento. Semelhante variabilidade só poderá subsumir o real atrativo do ensino criativo se for concebida nos moldes de uma rede cibernética de sinapses, apta a emular uma atitude humana aberta e surpreendente. Como bem observou Onilza Martins, "é imprescindível que não ocorra uma aprendizagem linear e reprodutiva na Educação a Distância. A expectativa de difundir conhecimentos facilmente por via eletrônica torna o processo simplista e resumido e impede que o aluno pesquise, elabore e discorde de tudo que vem pronto." (Martins, 2008). 
Mas, afinal, o que é uma rede de sinapses? Da fisiologia do cérebro temos que as sinapses são as conexões entre os neurônios. Cada neurônio armazena sua cota de informação, de tal modo que as conexões ou sinapses que se estabelecem entre neurônios originam milhões de intelecções associativas necessárias ao ato de pensar. Novas conexões são possíveis e nascem de estímulos ao raciocínio, principalmente ao raciocínio abstrato. $\mathrm{O}$ cérebro é, assim, uma rede de sinapses altamente complexa cujos nós são as células especializadas que denominamos neurônios.

Certamente, transpor o conceito de rede de sinapses de maneira pragmática para o EaD não é tarefa simples. Vamos entendê-la primeiramente em nível conceitual. $O$ neurônio em $\mathrm{EaD}$ é representado por um determinado núcleo de informação, isto é, um conteúdo armazenado. Pelo conceito de rede inteligente, vários conteúdos no estado fundamental do sistema (antes do primeiro acesso do aprendiz) devem estar associados segundo alguma topologia, e serão passíveis de novas associações (sinapses) conforme o estímulo exterior (participação do aprendiz). Para que esta simulação seja possível, o autor da aplicação simuladora deverá prever o maior número de conexões prováveis, deixando-as "latentes" até o momento em que sejam "provocadas" pelo aluno. Toda a trajetória do aluno é gravada e pontuada passo-a-passo segundo critérios de avaliação pré-estabelecidos. Cada trajetória poderá futuramente ser consultada durante a instrução de outro aluno, caso ocorra uma situação em que o serviço autômato de varredura encontre semelhanças úteis (reaproveitamento de ciclo).

A idéia da rede de sinapses também radica no conceito de hipertexto, se bem que aqui inexista o simulacro dinâmico da autonomia inteligente. Mas a ramificação em árvore de conteúdos conexos, constituindo percursos possíveis de aprendizagem virtualmente ilimitados, é inteiramente análoga à disposição instantânea de uma rede de sinapses.

Formalmente, podemos dizer que um motor de inteligência artificial (doravante IA) aplicado em EaD é um mapa $M$ sobre $i$ conteúdos $C_{i}$, dotado de uma topologia $T$, que leva uma determinada conexão sináptica $S$ em uma intelecção $I$ de tal maneira que,

$$
M_{i(T)}: S_{i}\left\langle C_{1}, C_{2}, C_{3}, \ldots C_{i}\right\rangle_{(T)} \Rightarrow I_{i(T)}
$$

A intelecção $I$ é, para todos os propósitos práticos, o entendimento que o aluno estrutura a partir das articulações realizadas entre os diversos conteúdos de uma trajetória instrucional. A topologia $T$ define a sequiência lógica dos assuntos (por exemplo, um conteúdo $C_{k}$ só é acessível se os conteúdos $C_{i}$ e $C_{j}$ já tiverem sido assimilados); ela prescreve a ordem didática com que determinados conteúdos devem ser apresentados. Por exemplo, seja a articulação sináptica,

$$
\underset{i=1, . ., 3 ; j=4}{S}\left\langle C_{i}, C_{j}\right\rangle_{(T)}:=\left\langle\left\langle C_{1} \succ\left\langle C_{2} \prec \succ C_{3}\right\rangle\right\rangle \succ C_{4}\right\rangle .
$$


O símbolo $\succ$ significa trajetória semântica de sentido único de um conteúdo para outro, enquanto $\prec \succ$ denota transitividade entre conteúdos. Os símbolos "〈" (bra) e "〉" (ket) delimitam os diversos blocos de conhecimentos articulados que formam assim conhecimentos superiores. A topologia $T$ nos assegura que do conteúdo $C_{1}$ se chega tanto ao conteúdo $C_{2}$ quanto ao $C_{3}$, sendo que o acesso a um deles remeterá automaticamente ao outro, mas somente partindo de $C_{1}$ e chegando a estes últimos é que se alcança o conteúdo $C_{4}$.

Amplas cadeias de conteúdos conexos podem ser representadas dessa maneira, sendo então documentadas as topologias requeridas. Estruturas mais complexas aparecem dando origem a cadeias de cadeias, isto é, sequiências de trilhas que só podem ser percorridas após o percurso de outras. Seja, por exemplo, a intelecção anterior conexa a duas trilhas subseqüentes possíveis, $(\hat{\kappa})$ e $(\hat{\lambda})$, cada qual com topologia associada a uma probabilidade determinada pelas rotas anteriores, respectivamente $\hat{\kappa} \mathrm{e} \hat{\lambda}$. Então,

$$
\begin{aligned}
& \operatorname{Sin}_{\mu=5, \ldots, 8 ; v=9}\left\langle C_{\mu}, C_{v}\right\rangle_{(\hat{\kappa})}:=\left\langle\left\langle\left\langle C_{5} \succ C_{6}\right\rangle \prec \succ\left\langle C_{7} \succ C_{8}\right\rangle\right\rangle \succ C_{9}\right\rangle ; \\
& S_{\mu=5, \ldots, 8 ; \eta=10}\left\langle C_{\mu}, C_{\eta}\right\rangle_{(\hat{\lambda})}:=\left\langle\left\langle\left\langle C_{5} \succ C_{6}\right\rangle \prec \succ\left\langle C_{7} \succ C_{8}\right\rangle\right\rangle \succ C_{10}\right\rangle ; \\
& I_{i(T)} \succ \\
& \left.\succ\left\langle\left\langle\left\langle\left\langle C_{5} \succ C_{6}\right\rangle \prec \succ\left\langle C_{7} \succ C_{8}\right\rangle\right\rangle \succ C_{9}\right\rangle\right|\left\langle\left\langle\left\langle C_{5} \succ C_{6}\right\rangle \prec \succ\left\langle C_{7} \succ C_{8}\right\rangle\right\rangle \succ C_{10}\right\rangle\right) \text {; } \\
& I_{i(T)} \succ\left\langle\begin{array}{c|c}
S_{\hat{\kappa}} & S_{\hat{\lambda}} \\
\mu \nu & \mu \eta
\end{array}\right| .
\end{aligned}
$$

Assim, a conexão entre a intelecção (1) e as trilhas (3) e (4) é puramente probabilística até que o agente instrutor decida por uma trilha com base no histórico registrado durante a construção da intelecção (1).

Vê-se que para a implementação da rede de sinapses faz-se absolutamente imprescindível o mapeamento prévio completo dos conteúdos a serem transmitidos, bem como das trilhas instrucionais preliminares definidas sob critérios pedagógicos e didáticos rigorosos. O domínio completo da metalinguagem esboçada acima, bem como do modelo probabilístico a ser aplicado, está além dos limites deste artigo. Entretanto, o autor deverá publicar em breve um trabalho específico sobre o assunto. 


\section{MEMÓRIAS SOBRE EaD}

Embora o termo "ensino a distância" venha sendo empregado há no mínimo um século, foi apenas em meados da década de oitenta que ocorreram no Brasil as primeiras iniciativas sérias no sentido de introduzir no processo instrucional, por meio das então novas tecnologias microinformáticas, um modo de aprendizagem no qual professor e aluno não se encontram simultaneamente no mesmo recinto físico. Adeptos e simpatizantes dos recémchegados programas estrangeiros de treinamento baseado em computador, ou TBC, pouco a pouco tomavam acento às mesas sobre os rumos do ensino moderno diante das dificuldades econômicas e geográficas delineadas no território brasileiro. Nessa época, quando estive à frente de uma divisão de multimeios, denominada "Sistemas Instrucionais Avançados" na Empresa de Processamento de Dados da Previdência Social — DATAPREV, tive a oportunidade e o prazer de ter conhecido e interagido pessoalmente com alguns dos grandes nomes mundialmente aclamados no que diz respeito à formação de recursos humanos como Alexander Romiszowski, Thomas Gilbert (já falecido), Barbara Grabowski e John Franklin Arce, de quem fui aluno, tendo inclusive produzido com ele uma aplicação para capacitação em estatística desenvolvida em Pascal, o Statmaster, e outras aplicações instrucionais para computadores pessoais em Pilot, antiga linguagem originariamente desenvolvida para ambientes de grande porte na década de sessenta. Gilbert fora responsável, já nos anos sessenta, pela introdução criativa de um modelo de design instrucional extremamente eficaz, baseado em princípios behavioristas, sob a designação de "matética" (mathetics no original em inglês). A palavra "matética" vem do grego e significa estudo ou aprendizagem. Gilbert estudou com o famoso psicólogo comportamental B. F. Skinner na Harvard University. Foi no âmbito corporativo que ele encontrou maior eco para a sua importante contribuição na área de treinamento, desenvolvimento e gestão de recursos humanos. Grabowski é atualmente Professor of Instructional Systems at Penn State University, Pennsylvania, e Associate Professor at Syracuse University, além de outras atividades não menos importantes. Quando a conheci, se a memória não me trai, era responsável pelo programa de treinamento por simulação para pilotos nas forças armadas norte-americanas. Romiszowski, também da Syracuse University, é talvez o mais conhecido de todos, tendo realizado numerosos trabalhos nos campos do design instrucional, desenvolvimento e avaliação. Sempre interagiu muito com o Brasil. John Franklin é doutor em estatística e ciência da computação pela Toronto University, e especialista em metodologia Seis Sigma pela Texas University. Além de ser um excelente mentor, é uma pessoa generosa e afável. Estimulado por ele, desenvolvi o conceito de rede de sinapses, muito posteriormente identificado nas bases da idéia de rede neural. Esses grandes homens, além de meus próprios pais, educadores por excelência, deram-me os fundamentos filosóficos, psicológicos e sócio-culturais corretos para que eu não me perdesse no verdadeiro cipoal de equívocos que viriam a ser cometidos mais tarde na educação brasileira como um todo, tais como os que advieram da freqüente precariedade das técnicas de avaliação/controle de qualidade.

Desde os anos 90, a literatura estrangeira sobre EaD tem sido abundante, agregando contribuições meritórias em trabalhos como os de Garrison (1990), Bracey (1992), Oblinger (2000), Soller (2004), Moore \& Kearsley (2005), Tabor (2007), e Vaughan (2010), entre tantos outros. Apesar de muito debate e esforço, a tecnologia computacional 
no Brasil não chegaria verdadeiramente a conquistar especialistas em educação e pedagogos, ainda ancorados às técnicas convencionais de organização da instrução, antes do advento da internet (1995/96), época em que o ensino a distância foi introduzido no sistema de ensino brasileiro com a promulgação da Lei de Diretrizes e Bases como uma modalidade de ensino, dita não presencial, em que os alunos receberiam aulas por meio de $\mathrm{TV}$, telefone ou Internet, sem a obrigatoriedade de ir à escola. Foi a conexão entre redes de computadores que de fato permitiu, via protocolo www (world wide web), o avanço do processo de ensino/aprendizagem para além dos limites da sala de aula e além do contexto da relação aluno/professor tradicional, criando oportunidades para o discente construir o conhecimento no próprio ambiente doméstico, de trabalho ou qualquer outro. Regiões outrora inacessíveis ao melhor da civilização em termos de educação, pessoas sobrecarregadas de afazeres diários e sem perspectivas de maior capacitação profissional por razões econômicas, viam assim, diante de si, um novíssimo horizonte de possibilidades a ser descortinado. Não obstante esse ganho absolutamente inegável, o distanciamento físico professor/aluno iria restringir de maneira drástica a aquisição de valores humanos intangíveis agregados ao processo interativo presencial inclusive no tocante aos métodos de avaliação disponíveis. Coisas como o convencimento pela postura, a clareza gestual, a influência geral da personalidade fisicamente presente, o prazer da conversa e a possibilidade do banimento da dúvida no momento em que ela surge, ficariam perdidos e com eles considerável parcela de tudo o que importa para uma boa formação em todos os sentidos. Já nos idos anos oitenta, defendia-se um ensino particionado, com aulas presenciais de um lado e interação computacional de outro, garantindo a cibernética e o humano em harmonia. Em particular, sempre fui defensor dessa posição, mesmo porque penso que a principal força e a principal fraqueza do $\mathrm{EaD}$ estão em sua maior vantagem: a flexibilidade. A rigor, este assunto foi mesmo o centro das minhas discussões acadêmicas com John Franklin, quando balizávamos o cerne metodológico do pacote estatístico no qual trabalhávamos.

Não que o ideal da combinação de metodologias antigas e novas tenha sido abandonado, fato é que na prática cada vez mais cursos a distância são oferecidos com pouca ou nenhuma interação presencial. Contudo, também é um fato que em níveis mais elevados de aprendizagem, isto é, que não necessariamente envolvem refinamentos comunicacionais nem requisitos de formação de personalidade, o tutor a distância supre, na maioria das vezes, as funções de um professor em classe. Nesse caso, incluem-se os cursos corporativos de capacitação e instrumentação específicas em determinadas técnicas administrativas ou no uso de ferramentas de software. Com efeito, sou de opinião que, se a Internet inexoravelmente nos torpedeia com toneladas de informação, então que essa informação seja submetida tanto quanto possível ao trabalho sistemático e crítico dos professores. Em 2004, segundo estudos do Centro de Informática Aplicada da Fundação Getúlio Vargas, estimava-se que o Brasil possuía cerca de 40 mil matriculados em cursos superiores a distância, sendo que, desse total, pelo menos 39 mil participavam para lecionar a distância. Embora não tenha notícias sobre o número atual, é de se supor que tenha havido considerável incremento a julgar pela crescente quantidade de iniciativas nesse domínio. Tal número pode ser um indicativo tranqüilizador em termos de que os conteúdos estejam sendo responsavelmente produzidos por pessoas competentes nas áreas de ensino/aprendizagem. A propósito dessa questão, tenho me dedicado à elaboração de ontologias para reaproveitamento eficiente dos grandes volumes de material pedagógico 
produzidos em EaD. Aqui, merecem nota os esforços do DATASUS - Departamento de Informática do Sistema Único de Saúde - , especialmente no que concerne à capacitação elementar em ferramentas para a construção da informação de apoio à decisão, ao conhecimento dos mecanismos que sustentam o funcionamento do SUS, à apresentação dos principais aspectos presentes no $\mathrm{EaD}$, assim como as principais tendências nesta área, e à estimulação de um olhar interdisciplinar capaz de captar as múltiplas relações implicadas no temário saúde. A criação do UniverSUS foi, sem dúvida, um marco quanto ao uso das tecnologias da informação e comunicação (TIC) como instrumentos de apoio ao ensino/aprendizagem na esfera governamental. No UniverSUS, conforme se pode verificar na página de abertura do sítio localizado sob o domínio do DATASUS em "http://universus.datasus.gov.br/", são disponibilizados gratuitamente cursos on line voltados para a capacitação profissional, desenvolvidos pelo DATASUS ou em parceria com outras áreas do Ministério da Saúde e Secretarias. Há também a oferta de ambientes virtuais para o trabalho colaborativo de equipes do âmbito do SUS. Ainda no DATASUS, o projeto "TabLab", em particular, trouxe em si o entendimento da qualificação integrada do profissional, mantendo fundamentação multidisciplinar de enfoque do temário da saúde no processo instrucional e na fase posterior de trabalho colaborativo; trouxe igualmente a marca de uma visão estratégica situacional, ou, como Rivera enfatiza, do esforço por "uma dinâmica de direção que potencialize o diálogo gerador de compromissos" (Rivera, 2003). É do compromisso dos setores beneficiários da proposta que se pode derivar uma gestão responsável e concretamente amparada por dispositivos de apoio à decisão. Pressupondo um enredo comunicacional destinado a favorecer o consenso (o Verständigung de Habermas) e a troca ativa de informação numa práxis social dialógica constante que valoriza a condução da ação, o TabLab excedeu em muito o terreno da simples capacitação, indo mesmo ao encontro de mudanças organizacionais determinantes de modificações em nossas maneiras de pensar a saúde no Brasil. Priorizou a busca e a valorização do compromisso, espelhando grande preocupação com o sentido matrístico (Maturana, 1991) das relações entre as partes atuantes. Infelizmente, essa iniciativa não encontrou o eco institucional necessário ao seu progresso. No entanto, o projeto parece ganhar ânimo renovado, fora do âmbito da saúde, entre as áreas de auditoria do Ministério do Trabalho e Emprego.

\section{O VIRTUAL, O REAL E O HUMANO}

Faz alguns anos, propus chamarmos "erdospaço" (do alemão Erdo = "Terra" + "espaço") o novo "lugar geométrico" da humanidade, criado pela combinação dos espaços físico e digital. De fato, as ações do homem contemporâneo não se dão mais no espaço físico apenas, mas num complexo amálgama cibernético:

"Mas, o espaço da experiência geográfica contemporânea - o erdospaço - supera o fisicalismo dioturno das percepções indo fundirse ao espaço digital. Já não faz sentido separar o físico do informático, ainda menos se levarmos a sério o vaticínio da combinação substancial de homem e máquina como os cyborgs de Haraway (1991), as 


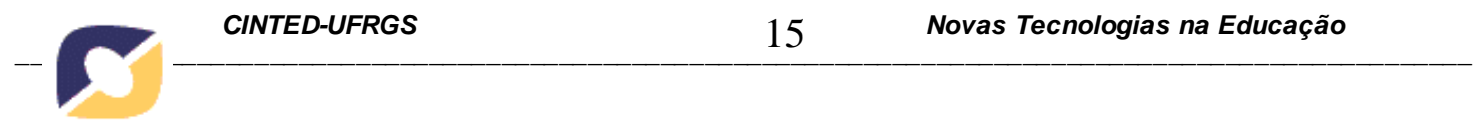

megamáquinas de Mumford (1970) - civilizações como máquinas do ponto de vista estrutural e operacional -, os coletivos homemmáquina de Latour (1993) - homens como atores planetários por via das redes - ou ainda as humáquinas de Luke (1989), verdadeiros coletivos de redes digitais, por sua vez, construções humanas manipuladas pela sociedade." (Serpa, 2002).

Evidentemente, o ensino se insere no paradigma da sociedade cibernética na medida em que a sala de aula física não mais existe sem o halo mediático das ações virtualizadas. Compreender o erdospaço é fundamental para perceber que estar num lugar não é mais uma situação geográfica e sim mediática. $\mathrm{O} \mathrm{EaD}$ é tão-somente uma consequiência natural do fato de vivermos agora no erdospaço. Com efeito, a interação homem/máquina consagra a realidade do erdospaço como a fusão do físico com o virtual. Charlotte Nirmalani Gunawardena, da University of New Mexico, e Marina Stock McIsaac, da Arizona State University, comentam que

"Virtual reality offers the promise of training future students in ways that currently are far too dangerous or expensive. Virtual reality combines the power of computer generated graphics with the computer's ability to monitor massive data inflows in real time to create an enclosed man/machine interactive feedback loop". (Gunawardena \& McIsaac, 2010).

Essa retroalimentação, ou feedback, é mais efetiva quanto mais humanizada for a interação, e, para tal humanização escalável, é requerida vasta interação sináptica se estivermos planejando a implementação do mestre cibernético. $\mathrm{O}$ erdospaço surge então como o meio através do qual homem e máquina conspiram para um único fim, o objetivo instrucional associado à elevação dos níveis de conhecimento.

Segundo Peters, EaD é "um método racional de partilhar conhecimento, habilidades e atitudes por meio da aplicação da divisão do trabalho e de princípios organizacionais, tanto quanto pelo uso extensivo de meios de comunicação, especialmente para o propósito de reproduzir materiais técnicos de alta qualidade, os quais tornam possível instruir um grande número de estudantes ao mesmo tempo, enquanto estes materiais durarem." (Peters, 1973). De acordo com Litwin, o moderno $\mathrm{EaD}$ "não se configura mais pela distância, pois a virtualidade possibilita encontros cada vez mais próximos e efetivos que promovem a educação". (Litwin, 2001). Garcia Aretio caracteriza uma aplicação de $\mathrm{EaD}$ como "um sistema de comunicação bidirecional, que substitui a interação pessoal entre professor e aluno pela ação sistemática conjunta de diversos recursos instrumentais e pelo apoio de um Centro Associado ou pólo que propicia todas as condições para a aprendizagem autônoma dos estudantes com a participação efetiva de tutores altamente qualificados". (Garcia Aretio, 1994). Estas afirmações se complementam hoje por intermédio das TIC em produtos consolidados que agregam diversos dispositivos e efeituadores capazes de propiciar em tempo real a assimilação comunal de conhecimentos e a produção colaborativa de diversos artefatos. 
Muito tem avançado a tecnologia de sistemas concebidos para atender aos distintos cenários de comunicação requeridos para a realização da complexidade laboral comentada acima. Uma das linhas evolutivas mais concorridas é a dos ambientes de teleconferências, ideais para relacionamentos remotos. Teleconferência é uma reunião virtual através de um meio de telecomunicações, onde os participantes que estão separados por distâncias geográficas podem interagir uns com os outros simultaneamente. Sem pretender um estudo analítico dos tipos existentes de teleconferência em função da complexidade tecnológica empregada, gostaria apenas de citar Monson (1978), quem descreveu quatro componentes de design para teleconferências: a)- humanização, b)- participação, c)- estilo de mensagem e d)- feedback. Humanizar resume a ação de criar um clima de evidenciação da importância do indivíduo, superando a barreira da distância por meio da geração de uma rede de relacionamento sobre um grupo de trabalho. Participação é o processo de ir além da tecnologia, proporcionando oportunidades para a interação espontânea entre participantes (de certa forma, isto também subentende humanização se pensarmos que o tecnológico nunca deve superar o humano). Estilo de mensagem se refere a apresentar o que está sendo dito de tal maneira que sejam garantidos o recebimento, o entendimento e a lembrança da mensagem. Finalmente, feedback é o processo de obtenção de informações a partir da mensagem recebida, ajudando o instrutor ou conferencista e os participantes a completarem o ciclo de comunicação.

A principal característica de tais sistemas é a de oferecer todos os recursos presentes em ambientes reais a custos reduzidos e operando em web browsers (Windows, Mac OS ou Linux). Permitem a interatividade entre várias pessoas e a transmissão de informações em um ambiente virtual onde cada participante pode ver e ouvir os demais, interagindo com eles como se todos estivessem fisicamente próximos. Estes sistemas se prestam em particular a três utilizações intimamente interligadas: educação, formação de comunidades virtuais e gestão do conhecimento. Sob esse prisma, a dimensão do humano parece ganhar expressão na medida em que o treinamento ou a comunicação envolvendo grande número de pessoas distantes entre si ocorre com vídeo e voz incorporados de maneira ágil e uniforme. Todas as ferramentas típicas da moderna dinâmica de ensino/aprendizagem podem ser concomitantemente utilizadas, tais como apresentações em PowerPoint, trabalhos colaborativos em real time usando processador de texto e lousa on line, pesquisas de opinião (enquetes), transferência de arquivos, chats e anotações pessoais com bloco de notas. Cabe lembrar que em tecnologia de transmissão de imagens, intensos esforços têm sido empreendidos na construção de algoritmos capazes de compor uma imagem básica, atualizando-a somente nas áreas onde houver movimento ou alteração de luminosidade, elevando assim o grau de sincronismo do processo, bem como a qualidade visual.

\subsection{JOGOS INSTRUCIONAIS}

Durante um bom tempo, os videogames foram ignorados pelos educadores. Isto se deveu principalmente ao fato de que é sobre as consequiências sociais de jogar que concentramos nossas preocupações, ignorando as importantes potencialidades para o ensino que os jogos oferecem. Devido à influência penetrante dos videogames sobre a cultura 
popular, muitos educadores mostraram interesse em estudar que efeitos esses jogos exercem sobre os jogadores, e como alguns dos seus componentes motivadores podem ser aproveitados para facilitar a aprendizagem, integrando-os ao design instrucional (Bowman, 1982; Bracey,1992; Driskell \& Dwyer, 1984). Bowman, por exemplo, sugere que os educadores podem usar videogames como modelos para melhoria dos ambientes de aprendizagem, fornecendo objetivos claros num contexto desafiador, permitindo a colaboração, dando aos estudantes maior controle sobre o processo de aprendizagem, tudo isso sob a operacionalização de critérios de avaliação baseados nas fases dos jogos. Bowman afirma ainda que um bom design instrucional deve envolver os alunos naquilo que ele chamou de "estados de fluxo", isto é, comportamentos contínuos que mantém os aprendizes focados em transpor as situações apresentadas, perseguindo metas significativas para eles.

A pesquisa de videogames revela muitos padrões da forma como os humanos interagem com a tecnologia, padrões estes que se tornam cada vez mais importantes para os tecnólogos de ensino que vêm a se tornar verdadeiros designers de ambientes digitais. Além disso, resgata o papel do ato de brincar no âmbito da atividade intelectual. Não tenho dúvidas de que o enfrentamento de problemas sem medo e com o espírito da diversão leva não apenas à solução de tais problemas, mas a soluções muitas vezes criativas e inovadoras. Vai daí a importância da cultura infanto-juvenil dos quadrinhos a manter acesa, se bem equilibrada com a educação sistemática, a chama da inventividade e dos devaneios, afinal, os agentes primeiros do crescimento humano. Eu mesmo, no final dos anos oitenta, ressaltava a importância do aspecto lúdico na aprendizagem, partindo de observações feitas por Huizinga sobre o mundo animal (Serpa, 1989).

Os jogos instrucionais constituem um nicho relativamente pouco explorado no Brasil. Nessa linha, sob patrocínio acadêmico vinculado à Universidade Federal Rural do Rio de Janeiro, desenvolvi entre os anos 2000 e 2002 uma aplicação on line na área do agronegócio voltada ao treinamento de consultores rurais de negócios. Atualmente, como sóciofundador da empresa TechSolarium - Tecnologia Solar LTDA —, cujo contrato social inclui responsabilidade em treinamento e educação, me dedico também à criação de jogos para o ensino de História do Brasil como parte de um projeto educacional amplo destinado às escolas públicas de vários estados. Em parceria com Leandro Serpa, foi implementada uma complexa realidade em 3D com mais de 200 artefatos para a implementação de jogos (roupas em geral, efeitos especiais, personagens variados, etc.), os quais podem ser ofertados e distribuídos por módulos. Para a construção célere e organizada dos jogos, garantindo o atendimento objetivo das demandas de mercado, construímos um engine robusto com diversos componentes especializados de desenvolvimento. Dominamos completamente a arte do desenho e da composição musical, produzindo inclusive as trilhas sonoras e demais requisitos sonoplásticos necessários.

Particularmente com foco instrucional, Leandro Serpa propõe que as redes de sinapses podem assumir configuração ótica por meio do que ele denominou "agentes inteligentes virtuais visuais" (AIVV), aperfeiçoando ainda mais a emulação do mestre com a introdução de animações faciais e gestuais em 3D, transformando dados em ações (comandos) que produzem determinada trilha de movimentação gráfica capaz de se ramificar em várias outras cujas escolhas serão probabilísticas sobre o peso das trilhas anteriores. É importante 
frisar que a rede de sinapses estrutura as conexões entre conteúdos, mas cada neurônio pressupõe a existência de máquinas de estado, motores que determinam os percursos virtuais das trilhas de informação, garantindo a evolução do estado de conhecimento do aluno.

\section{CONCLUSÃO}

Este artigo apresentou uma visão objetiva do ensino a distância, apontando certa direção de pesquisa teórica original avançada, incluindo princípios de representação formal da emulação de processos inteligentes de ensino, e corrigindo uma falha importante no registro convencional da história do $\mathrm{EaD}$ no Brasil. Além disso, indicou a necessidade de maior apoio à pesquisa e ao desenvolvimento na área de jogos instrucionais, ainda tímida na moderna cultura acadêmica brasileira. $\mathrm{O}$ EaD cibernético, principal idéia desenvolvida aqui, é opção que ainda demandará muito trabalho. Seria Interessante que a Universidade Paulista - UNIP, uma das instituições de ensino que mais aderiu à prática do $\mathrm{EaD}$ nos últimos tempos, constituísse um grupo de pesquisa permanente nessa área, oferecendo vagas para alunos de iniciação científica que desejassem seguir estudos em inteligência artificial. Não seria desarrazoado pensar inclusive na criação de um curso superior em EaD constituído por ampla grade híbrida de humanismos e tecnologias com grande apelo filosófico. Lembro que tal iniciativa condiz plenamente com os esforços da Casa para obtenção da nota máxima de avaliação do MEC nos cursos relacionados à tecnologia da informação, além de que alcançar excelência em EaD significa estar na vanguarda das TIC e da responsabilidade social de ensinar com qualidade e modernidade. Parafraseando Romiszowski, em plena sociedade do conhecimento, creio ser fundamental que as instituições de ensino ajudem os cidadãos a desenvolverem capacidades para o trabalho com múltiplos conhecimentos, isto é, habilidades de usar conhecimentos existentes e dominados para construir novos conhecimentos que possam ser úteis à solução de problemas, frente às oportunidades sempre presentes a nossa volta. Nada mais adequado do que fazer isto com o auxílio do $\mathrm{EaD}$, com todas as suas facilidades e motivações para o mundo da informática.

\section{$\cos 80$}

\section{AGRADECIMENTOS}

Sou muito grato ao Prof. Ly pelas sucessivas oportunidades de divulgação do meu trabalho acadêmico e pela generosidade com que dispõe do seu tempo para os colegas. Agradeço ao corpo docente da UNIP, bem como ao corpo administrativo da mesma, especialmente ao Prof. Bandeira e ao Prof. Diego pela confiança profissional sempre manifesta. Agradeço ao meu sobrinho, Leandro Serpa, pela constante e enriquecedora parceria. 


\section{REFERÊNCIAS}

BOWMAN, R. (1982). A Pac-Man theory of motivation. Tactical implications for classroom instruction. Educational Technology, 22(9), 14-17.

BRACEY, G. The bright future of integrated learning systems. Educational Technology, 32(9), 60-62, 1992.

BUNGE, M. Ciência e desenvolvimento. São Paulo: Itatiaia, 1980.

DRISKELL, J.; DWYER, D. Microcomputer videogame based training. Educational Technology, 24(2), 11-15, 1984.

DRUCKER, P. Managing for the future: the 1990s and beyond. New York: Penguin, 1992.

GARCIA ARETIO, L. La educacion a distancia: de la teoria a la practica. Madrid: Ariel, 2002.

GARRISON, D. An analysis and evaluation of audio teleconferencing to facilitate education at a distance. The American Journal of Distance Education, 4(3), 13-24, 1990.

GERY, G. Making cbt happen. Dover: New York, 1987.

GUNAWARDENA, C.; McISAAC, M. Distance education. 2010. Disponível em: 〈http:/citeseerx.ist.psu.edu/viewdod \. Acesso em 22 Jun. 2011.

HARAWAY, D. Simians, cyborgs and women. New York: Routledge, 1991.

LATOUR, B. We have never been modern. Massachusetts: Harvard, 1993.

LATOUR, B. On recalling ANT. In: LAW, J.; HASSARD, J. (Ed). Actor network theory and after. Oxford: Blackwell, 1999.

LÉVY, P. A conexão planetária: o mercado, o ciberespaço, a consciência. São Paulo: Editora 34, 2001.

LITWIN, E. Educação a distância: temas para o debate de uma nova agenda educativa. Porto Alegre: Artmed, 2001.

LUKE, T. Screens of power: ideology, domination and resistance in informational society. Urbana: University of Illinois Press, 1989.

MOORE, M.; KEARSLEY, G. Distance education: a systems view. Belmont - CA: Wadsworth, 2005. 
MARTINS, O. Os caminhos da EaD no Brasil. Rev. Diálogo Educ., 8(24): 357-371, 2008.

MATURANA, H. El sentido de lo humano. Santiago de Chile: Hachette, 1991.

MONSON, M. Bridging the distance: an instructional guide to teleconferencing. Madison-WI: Instructional Communications Systems, 1978.

OBLINGER, D. The nature and purpose of distance education. The Technology Source, Michigan Virtual University, 2000. Disponível em: 〈http://www.mivu.org/〉. Acesso em: 25 Mai. 2011.

PETERS, O. Die didaktische struktur des fernunterrichts. Weinheim: Beltz, 1973.

PIAGET, J. O nascimento da inteligência na criança. Rio de Janeiro: Zahar, 1982.

RIVERA, J. Análise estratégica em saúde e gestão pela escuta. Rio de Janeiro: FioCruz, 2003.

ROMISZOWSKI, A. Individualization of teaching and learning: where have we been; where are we going? Journal of Special Education Technology, p.2: 182, 1994.

SERPA, N. Cibernética, tbc e jogos instrucionais. In: INFOPREV 89, 1989, Rio de Janeiro. Anais. Rio de Janeiro: DATAPREV.

SERPA, Nilo S. C. Reversões geopolíticas: geografia, física e filosofia na sociedade globalizada. Rio de Janeiro: Papel \& Virtual, 2002.

SIMON, H. Comportamento administrativo: estudo dos processos decisórios nas organizações administrativas. Rio de Janeiro: Fundação Getúlio Vargas, 1965.

SOLLER, A. Computational modeling and analysis of knowledge sharing in collaborative distance learning. User modeling and user-adapted interaction. The Journal of Personalization Research, 14(4), 351-381, 2004.

TABOR, S. Narrowing the distance: implementing a hybrid learning model. Quarterly Review of Distance Education (IAP), 8(1): 48-49, 2007.

VAUGHAN, N. Blended learning. In: Cleveland-Innes, M.; Garrison, D. An introduction to distance education: understanding teaching and learning in a new era. Taylor \& Francis, 2010. p. 165. 